\begin{tabular}{|c|c|c|}
\hline \multirow{3}{*}{$\begin{array}{r}\text { Case Reports in } \\
\text { Gastroenterology }\end{array}$} & \multirow{2}{*}{\multicolumn{2}{|c|}{ Case Rep Gastroenterol 2015;9:221-226 }} \\
\hline & & \\
\hline & $\begin{array}{l}\text { DOI: } 10.1159 / 000437048 \\
\text { Publisnea onine: July } 9,2015\end{array}$ & $\begin{array}{l}\text { (c) } 2015 \text { S. Karger AG, Basel } \\
\text { 1662-0631/15/0092-0221 } \$ 39.50 / 0 \\
\text { www.karger.com/crg }\end{array}$ \\
\hline & \multicolumn{2}{|c|}{$\begin{array}{l}\text { This is an Open Access article licensed under the terms of the Creative Common } \\
\text { Attribution-NonCommercial } 3.0 \text { Unported license (CC BY-NC) (www.karger.com/OA } \\
\text { license), applicable to the online version of the article only. Distribution permitted for non } \\
\text { commercial purposes only. }\end{array}$} \\
\hline
\end{tabular}

\title{
Glycogenic Hepatopathy: Thinking Outside the Box
}

\author{
Nishant Parmar ${ }^{a}$ Muslim Atiq $^{\mathrm{b}} \quad$ Lee Austin $^{\mathrm{b}}$ Ross A. Miller \\ Thomas Smyrk $^{d} \quad$ Kabir Ahmed ${ }^{a}$ \\ ${ }^{a}$ Department of Internal Medicine, Sanford USD School of Medicine and \\ ${ }^{b}$ Sanford Center for Digestive Health, Sanford USD Medical Center, Sioux Falls, \\ S. Dak., 'Department of Pathology, The Methodist Hospital, Houston, Tex., \\ and ${ }^{\mathrm{d}}$ Department of Laboratory Medicine and Pathology, Mayo Clinic, \\ Rochester, Minn., USA
}

\section{Key Words}

Glycogenic hepatopathy · Hepatomegaly · Elevated liver enzymes · Non-alcoholic fatty liver disease $\cdot$ Celiac disease $\cdot$ Dual-echo magnetic resonance imaging

\begin{abstract}
Glycogenic hepatopathy $(\mathrm{GH})$ remains underrecognized in adults as most clinicians mistake it for the more common hepatic abnormality associated with uncontrolled diabetes mellitus in this age group, non-alcoholic fatty liver disease. This is also complicated by the fact that both entities are indistinguishable on liver ultrasound. We herein describe a similar predicament in which a young adult female presented with bilateral upper quadrant abdominal pain, tender hepatomegaly, lactic acidosis and a $>10$-fold increase in liver enzymes, which worsened after the administration of high-dose steroids. Despite intravenous normal saline resuscitation, serum transaminitis persisted in a fluctuating manner. Ultimately, a liver biopsy confirmed GH. Biochemically, GH is driven by high amounts of both circulating glucose and insulin or by the administration of high-dose steroids. Improving glycemic control is the mainstay of treatment for $\mathrm{GH}$. However, in our case, improvement in glycated hemoglobin of just $0.6 \%$ was enough to achieve symptomatic relief, supporting recent claims of the involvement of other identified factors in disease development.

(c) 2015 S. Karger AG, Basel
\end{abstract}


Parmar et al.: Glycogenic Hepatopathy: Thinking Outside the Box

\section{Introduction}

In 1930, Mauriac [1] first described abnormal glycogen deposition, hepatomegaly and abnormal liver enzymes associated with growth retardation, delayed puberty, cushingoid features and hypercholesterolemia in children with uncontrolled type 1 diabetes mellitus (DM). Since then, it has been revealed that such hepatic glycogen accumulation can occur independently of the aforementioned extrahepatic manifestations of Mauriac syndrome. Over the years, this abnormality has been termed hepatic glycogenosis [2], liver glycogen storage [3], liver glycogenosis [4] and DM-associated glycogen storage hepatomegaly [5]. Most recently, Torbenson et al. [6] designated this entity as glycogenic hepatopathy (GH).

Although heavily documented, GH remains underrecognized. This is especially the case in the adult population, where the more common liver abnormality associated with uncontrolled DM is considered to be non-alcoholic fatty liver disease (NAFLD). The two are indistinguishable on liver ultrasound [7], often causing clinicians to misdiagnose GH as NAFLD. In the following, we add to the already sizeable collection of GH cases. This case identifies the challenge that generalists and specialists face when diagnosing $\mathrm{GH}$, especially in the adult population.

\section{Case Presentation}

A 21-year-old female with a history of celiac disease (CD) and uncontrolled type 1 DM with an average glycated hemoglobin (HbA1c) of $13.3 \%$ was transferred from an outside facility with bilateral upper quadrant abdominal pain and tender hepatomegaly on examination. The patient denied any diarrheal episodes and reported compliance to an outpatient gluten-free diet. At the outside facility, the initial presentation had been a pruritic facial rash with left ear swelling and dyspnea. Initial laboratory evaluation revealed aspartate transaminase (AST) 3,161 U/l and alanine aminotransferase (ALT) $590 \mathrm{U} / \mathrm{l}$. High-dose methylprednisolone was administered intravenously for the presenting symptoms. Serum liver panel drawn $4 \mathrm{~h}$ later showed an increase in AST and ALT to $>4,202$ and $973 \mathrm{U} / \mathrm{l}$, respectively. Prothrombin time, total bilirubin and alkaline phosphatase were within normal limits, with a slight decrease in serum albumin level. Serum lactic acid was elevated with an anion gap metabolic acidosis and ketonuria. Computed tomography (CT) of the abdomen and pelvis with intravenous contrast revealed hepatomegaly with fatty infiltration of the liver as well as large bowel (from transverse to descending colon) and small bowel (mid and distal ileal loops) wall thickening with few mildly distended loops of small bowel, mild edema, and fluid within the central mesentery. Intravenous resuscitation with a bolus of normal saline was given.

After transfer to our facility, the patient was started on an insulin drip along with continuation of normal saline resuscitation. A liver ultrasound with Doppler was performed, showing identical hepatic abnormalities as those seen on CT. On hospital day 5, the lactic acid normalized. Serum transaminases still persisted, but did so in a fluctuating manner.

Laboratory testing for autoimmune, infectious and drug-induced hepatitis was unremarkable. A liver biopsy was performed on day 3 after admission, revealing enlarged pale hepatocytes with slight microvesicular steatosis and prominent glycogenated nuclei without any ballooning or inflammation (fig. 1). Trichrome staining failed to reveal increased collagen deposition or fibrosis, but periodic acid-Schiff staining showed intracytoplasmic glycogen inclusions which disappeared after diastase administration, confirming GH. For the re- 
Parmar et al.: Glycogenic Hepatopathy: Thinking Outside the Box

mainder of the hospital stay, the rise and fall in liver function tests (LFTs) did not correlate with blood glucose levels.

With modest symptomatic improvement in abdominal pain and significant decrease in transaminases, the patient was discharged home. Upon follow-up 1 week later, symptoms were completely resolved, with normalization of LFTs.

\section{Discussion}

With the sharp incline in transaminases, the possible differentials of abdominal pain and hepatomegaly include ischemic hepatitis and autoimmune hepatitis. Ischemic hepatitis can present with lactic acidosis, however, lactic acidosis is also seen with diabetic ketoacidosis $[8,9]$, which was also noted in our case.

Autoimmune hepatitis is also commonly seen with CD [10]. Moreover, a study performed in 1995 showed elevated LFTs in $40 \%$ of patients with undiagnosed and therefore untreated CD [11]. More recent inquiries have shown that transaminitis can be present in even treated cases [12]. Active CD exhibits a malabsorption pattern on CT causing the small bowel to appear dilated, fluid-filled and flaccid, causing telescoping and possible intussusception with large flatus-filled colon from excess gas production with fluid pluming in the right colon and encrusting of the right colonic wall [13]. The introductory CT in our case revealed distended loops of small bowel and edema to a mild degree, indicating adequate suppression of CD with gluten-free diet. In 2011, in a comprehensive review of the histologic characteristics of CD, Mounajjed et al. [14] showed liver biopsy results of 30 patients with CD. Of these patients, 19 had autoimmune-mediated liver disease (autoimmune hepatitis 9, primary sclerosing cholangitis 7 , and primary biliary cirrhosis 3 ). The remaining 11 patients had cryptogenic hepatitis (5), hepatitis C (2), steatohepatitis (2) sarcoidosis (1) and T-cell lymphoma (1). The liver disease diagnosis preceded the CD diagnosis in all groups except for steatohepatitis. However, these patients do not typically have such a sharp elevation of LFTs as described in our case. Furthermore, a $>10$-fold increase in liver enzymes has been commonly documented in many cases of $\mathrm{GH}$, with a disproportionately greater rise in AST versus ALT observed in our case [2, 3, 15-17].

Individuals with NAFLD also have a higher prevalence of CD [18]. On liver biopsy, NAFLD-defining lesions include a certain degree of steatosis with lobular inflammation, portal inflammation, hepatocyte ballooning and/or fibrosis. Instead, the histologic characteristics of GH were seen in our case, specifically pale, swollen hepatocytes with glycogenated nuclei and positive periodic acid-Schiff-stained intracytoplasmic inclusions that disappear after digestion with diastase [6,19]. Clinically, the two differ in that NAFLD is seen more in type $2 \mathrm{DM}$, happening as a result of insulin insensitivity from obesity and exhibiting the ability to progress to cirrhosis, while GH has occurred mostly with type $1 \mathrm{DM}$, with no evidence of progression to cirrhosis $[6,20]$. Other than in uncontrolled type $1 \mathrm{DM}$, the use of highdose corticosteroids has been identified as another precipitant of GH [21]. In our case, highdose corticosteroid administration served as more of an exacerbating factor, causing serologic worsening.

The pathophysiology of GH involves glucose freely diffusing from the plasma into a hepatocyte where it is trapped by its conversion to glucose-6-phosphate by glucokinase followed by conversion to glycogen by glycogen synthase. Initially inactive, glycogen synthase is activated as a consequence of dephosphorylation by phosphatase. The concentration and activity of phosphatase depend on insulin and the presence of glucose, respectively [22, 23]. In essence, large amounts of both plasma glucose and insulin are needed for the develop- 
Parmar et al.: Glycogenic Hepatopathy: Thinking Outside the Box

ment of GH, both of which are present in the setting of uncontrolled diabetes. A potential exacerbating factor are the frequent hypoglycemic episodes commonly seen in type $1 \mathrm{DM}$ that are subsequently treated with glucose administration, further fueling glycogen formation and deposition [22]. Fridell et al. [24] confirmed this by showing complete clinical and histologic resolution of GH by establishing euglycemia without exogenous insulin via pancreatic transplantation. This explains the persistence of transaminitis despite achieving periods of normalized blood sugars with insulin therapy in our case.

Improving glycemic control is the mainstay of treatment for $\mathrm{GH}$, with excellent prognosis in the form of complete symptomatic resolution as well as normalization of LFTs and liver size $[3,22,23,25-28]$. Recently, Cha et al. [15] challenged this and the notion that hyperglycemia from poor diabetes control and aggressive insulin therapy are the sole factors that drive GH. They documented three cases of GH, all of which exhibited resolution of transaminitis without aggressive insulin therapy or lowering of HbA1c. Upon further review, their first case did show biochemical resolution of GH with better glycemic control, however this happened without the HbA1c dropping below $11 \%$. Our case is similar in that an improvement of just $0.6 \%$ in $\mathrm{HbA} 1 \mathrm{c}$ led to symptomatic relief of abdominal pain and a decline of LFTs. No previous studies have been done on the degree of improvement in glycemic control needed in order to serologically and symptomatically resolve $\mathrm{GH}$, potentially explaining this phenomenon.

As seen in many cases including ours, liver biopsy has served as the only means of definitely diagnosing $\mathrm{GH}[6,17,23,25,28]$. However, non-invasive testing for diagnosis has been recently explored. Firstly, Sweetser and Kraichely [16] described the detection of GH via non-contrast CT, explaining that NAFLD results in a hypodense liver, while the liver of GH would be hyperdense. Murata et al. [29] argued that the liver on CT in GH can be hypodense due to co-existing acute liver injury, and subsequently recommended the addition of dualecho magnetic resonance imaging to the radiologic evaluation.

In conclusion, recent advancements have been made in obtaining better means of diagnosing GH, which should lessen the current level of difficulty for practitioners during such a clinical scenario. The need for further investigations still exists to resolve recent arguments that are challenging what is known of GH.

\section{Disclosure Statement}

The authors state no conflict of interest.

\section{References}

1 Mauriac P: Gros ventre, hépatomégalie, troubles de la croissance chez les enfants diabétiques traités depuis plusieurs années par l'insuline. Gaz Hebd Med Bordeaux 1930;26:402-410.

2 Cuthbertson DJ, Brennan G, Walsh S, Henry E: Hepatic glycogenosis: abnormal liver function tests in type 1 diabetes. Diabet Med 2007;24:322-323.

3 Torres M, Lopez D: Liver glycogen storage associated with uncontrolled type 1 diabetes mellitus. J Hepatol 2001;35:538.

4 Carcione L, Lombardo F, Messina MF, Rosano M, De Luca F: Liver glycogenosis as early manifestation in type 1 diabetes mellitus. Diabetes Nutr Metab 2003;16:182-184.

-5 Nakamuta M, Ohashi M, Goto K, Tanabe Y, Hiroshige K, Nawata H: Diabetes mellitus-associated glycogen storage hepatomegaly: report of a case and review of the Japanese literature. Fukuoka Igaku Zasshi 1993;84:354-358. 
Parmar et al.: Glycogenic Hepatopathy: Thinking Outside the Box

-6 Torbenson M, Chen YY, Brunt E, Cummings OW, Gottfried M, Jakate S, Liu YC, Yeh MM, Ferrell L: Glycogenic hepatopathy: an underrecognized hepatic complication of diabetes mellitus. Am J Surg Pathol 2006;30:508-513.

7 Krishnan B, Babu S, Walker J, Walker AB, Pappachan JM: Gastrointestinal complications of diabetes mellitus. World J Diabetes 2013;4:51-63.

-8 Kreisberg RA: Lactate homeostasis and lactic acidosis. Ann Intern Med 1980;92(2 Pt 1):227-237.

-9 Marliss EB, Ohman JL Jr, Aoki TT, Kozak GP: Altered redox state obscuring ketoacidosis in diabetic patients with lactic acidosis. N Engl J Med 1970;283:978-980.

10 Villalta D, Girolami D, Bidoli E, Bizzaro N, Tampoia M, Liguori M, Pradella M, Tonutti E, Tozzoli R: High prevalence of celiac disease in autoimmune hepatitis detected by anti-tissue transglutaminase autoantibodies. J Clin Lab Anal 2005;19:6-10.

-11 Bardella MT, Fraquelli M, Quatrini M, Molteni N, Bianchi P, Conte D: Prevalence of hypertransaminasemia in adult celiac patients and effect of gluten-free diet. Hepatology 1995;22:833-836.

12 Korpimäki S, Kaukinen K, Collin P, Haapala AM, Holm P, Laurila K, Kurppa K, Saavalainen P, Haimila K, Partanen J, Mäki M, Lähdeaho ML: Gluten-sensitive hypertransaminasemia in celiac disease: an infrequent and often subclinical finding. Am J Gastroenterol 2011;106:1689-1696.

13 Scholz FJ, Afnan J, Behr SC: CT findings in adult celiac disease. Radiographics 2011;31:977-992.

14 Mounajjed T, Oxentenko A, Shmidt E, Smyrk T: The liver in celiac disease: clinical manifestations, histologic features, and response to gluten-free diet in 30 patients. Am J Clin Pathol 2011;136:128-137.

15 Cha JH, Ra SH, Park YM, Ji YK, Lee JH, Park SY, Baik SK, Kwon SO, Cho MY, Kim MY: Three cases of glycogenic hepatopathy mimicking acute and relapsing hepatitis in type I diabetes mellitus. Clin Mol Hepatol 2013;19: 421-425.

16 Sweetser S, Kraichely RE: The bright liver of glycogenic hepatopathy. Hepatology 2010;51:711-712.

17 van den Brand M, Elving LD, Drenth JP, van Krieken JH: Glycogenic hepatopathy: a rare cause of elevated serum transaminases in diabetes mellitus. Neth J Med 2009;67:394-396.

18 Bakhshipour A, Kaykhaei MA, Moulaei N, Mashhadi MA: Prevalence of coeliac disease in patients with non-alcoholic fatty liver disease. Arab J Gastroenterol 2013;14:113-115.

19 Brunt EM, Tiniakos DG: Histopathology of nonalcoholic fatty liver disease. World J Gastroenterol 2010;16: 5286-5296.

20 Masuoka HC, Chalasani N: Nonalcoholic fatty liver disease: an emerging threat to obese and diabetic individuals. Ann N Y Acad Sci 2013;1281:106-122.

21 Iancu TC, Shiloh H, Dembo L: Hepatomegaly following short-term high-dose steroid therapy. J Pediatr Gastroenterol Nutr 1986;5:41-46.

22 Chatila R, West AB: Hepatomegaly and abnormal liver tests due to glycogenosis in adults with diabetes. Medicine (Baltimore) 1996;75:327-333.

-23 Munns CF, McCrossin RB, Thomsett MJ, Batch J: Hepatic glycogenosis: reversible hepatomegaly in type 1 diabetes. J Paediatr Child Health 2000;36:449-452.

24 Fridell JA, Saxena R, Chalasani NP, Goggins WC, Powelson JA, Cummings OW: Complete reversal of glycogen hepatopathy with pancreas transplantation: two cases. Transplantation 2007;83:84-86.

-25 Abaci A, Bekem O, Unuvar T, Ozer E, Bober E, Arslan N, Ozturk Y, Buyukgebiz A: Hepatic glycogenosis: a rare cause of hepatomegaly in type 1 diabetes mellitus. J Diabetes Complications 2008;22:325-328.

26 Hudacko RM, Manoukian AV, Schneider SH, Fyfe B: Clinical resolution of glycogenic hepatopathy following improved glycemic control. J Diabetes Complications 2008;22:329-330.

27 Saadi T: Glycogenic hepatopathy: a rare disease that can appear and resolve rapidly in parallel with glycemic control. Isr Med Assoc J 2012;14:269-270.

28 Saxena P, Turner I, McIndoe R: Education and Imaging. Hepatobiliary and pancreatic: glycogenic hepatopathy: a reversible condition. J Gastroenterol Hepatol 2010;25:646.

29 Murata F, Horie I, Ando T, Isomoto E, Hayashi H, Akazawa S, Ueki I, Nakamura K, Kobayashi M, Kuwahara H, Abiru N, Kawasaki E, Yamasaki H, Kawakami A: A case of glycogenic hepatopathy developed in a patient with new-onset fulminant type 1 diabetes: the role of image modalities in diagnosing hepatic glycogen deposition including gradient-dual-echo MRI. Endocr J 2012;59:669-676. 


\begin{tabular}{ll|l} 
Case Reports in & \multicolumn{2}{l}{ Case Rep Gastroenterol 2015;9:221-226 } \\
\cline { 2 - 3 } Gastroenterology & DOI: 10.1159/000437048 & $\begin{array}{l}\text { @ 2015 S. Karger AG, Basel } \\
\text { www.karger.com/crg }\end{array}$ \\
\cline { 2 - 2 } & Parmar et al.: Glycogenic Hepatopathy: Thinking Outside the Box
\end{tabular}

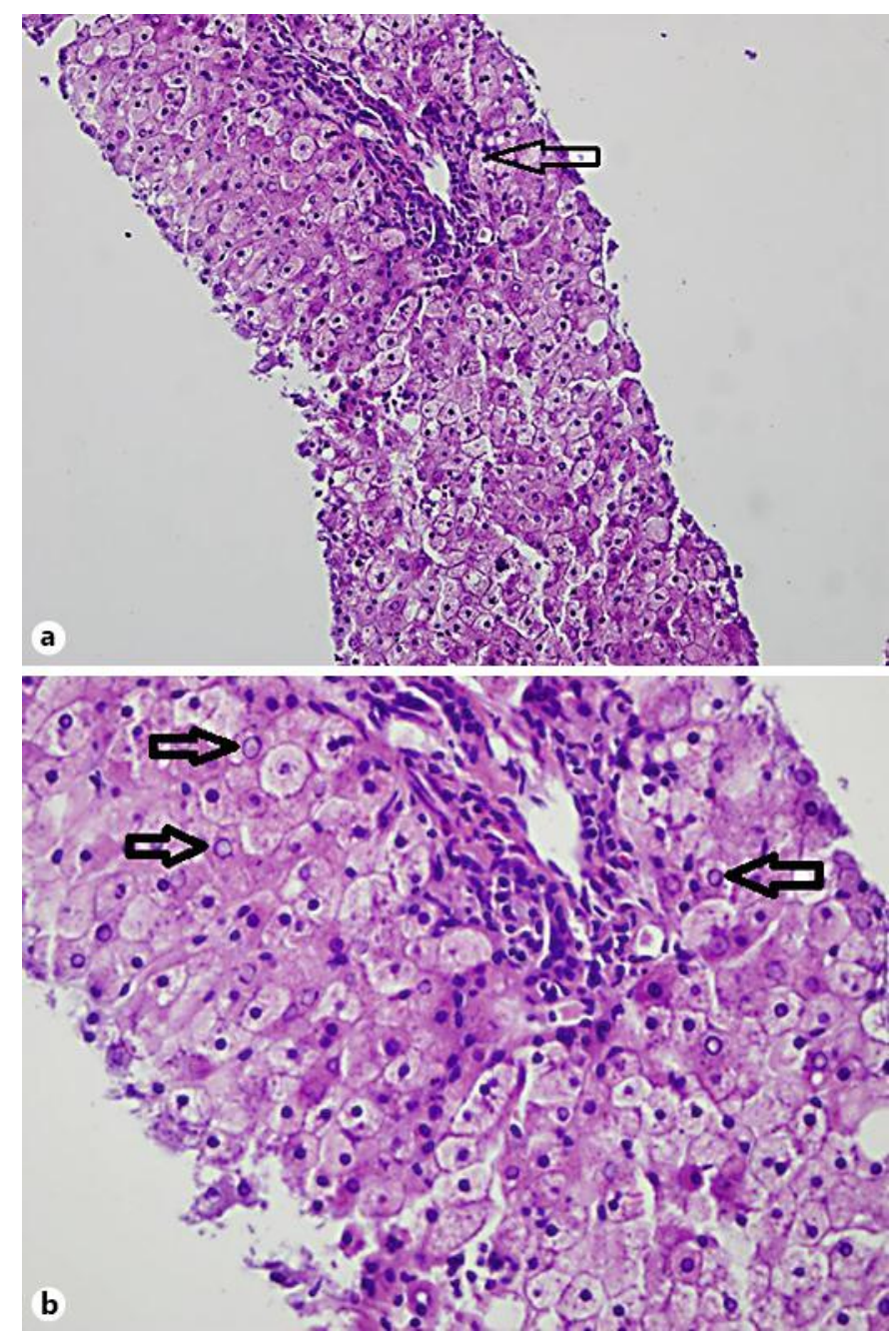

Fig. 1. a On this view, enlarged pale hepatocytes with slight microvesicular steatosis and prominent nuclei are seen. A portal triad can be visualized (arrow) and no significant inflammation or ballooned hepatocytes are seen. b A higher-power view readily shows glycogenated nuclei (arrows). 